\title{
Effect of Kind Rolling on the Properties of Plasma-Formed Nitride Layers on $\mathrm{Fe}_{93} \mathrm{Ni}_{4} \mathrm{Ti}_{3}$
}

\author{
Fayez Mahomoud El-Hossary ${ }^{1}$, Sayed Mohammed Khalil ${ }^{1,2}$, Magdy Abdel Wahab Kassem ${ }^{3}$, \\ Khaled Lotfy ${ }^{1}$ \\ ${ }^{1}$ Physics Department, Faculty of Science, Sohag University, Sohag, Egypt \\ ${ }^{2}$ Physics Department, University of Colorado at Boulder, Boulder, USA \\ ${ }^{3}$ Department of Materials and Metallurgical Engineering, Faculty of Petroleum and Mining Engineering, \\ Suez Canal University, Suez, Egypt \\ E-mail: khalil_20002000@yahoo.com \\ Received April 15, 2010; revised May 21, 2010; accepted June 10, 2010
}

\begin{abstract}
The nitriding behavior of cold rolled $\mathrm{Fe}_{93} \mathrm{Ni}_{4} \mathrm{Ti}_{3}$ specimens was compared with that of hot rolled specimens of the same materials. Radio frequency (rf) nitriding was performed for 10 minutes in a $10^{-2}$ mbar nitrogen atmosphere. The continuous plasma power was varied from $300-550 \mathrm{~W}$ in steps $50 \mathrm{~W}$ or less. Results of optical microscopy (OM), x-ray diffraction (XRD) and microhardness measurements (Hv) are presented and discussed with regard to the influence of kind rolling on the nitriding behavior, particularly nitride formation and nitride layer growth on mechanical properties. The results show a remarkable increase of nitrogen diffusivity and microhardness of cold rolled nitride samples. These best results may be attributed to enhancement of the defect and/or a compressive stress.
\end{abstract}

Keywords: Cold Rolled, Hot Rolled-Radio Frequency (Rf), Microhardness, Optical Microscopy (OM), X-Ray Diffraction (XRD)

\section{Introduction}

Surface plasma nitriding of steels is a well-established technique to produce a modified (hard) surface layer on steels or other iron based alloys with good anti-corrosive and wear resistance properties. Both the nitrogen case depth and the resulting nitride type commonly depend on the nitriding conditions as well as on the properties of material, such as composition, crystallographic structure and the density of various lattice defects. In particular, the thickness and the composition of the nitrided layer are strongly affected by the type of chemical reactions occurring at the specimen's surface as well as by the diffusivity of nitrogen in the treated material.

Nitrogen diffusivity in materials depends on many factors including lattice structure, grain size, chemical composition and defect density. In ultrafine-grained materials, which can be fabricated by consolidation of nanopowders [1,2], sever plastic deformation [3], hot rolling [4] and cold rolling [5], the increased grain boundary area and the dislocation density will promote the diffusion of alloying elements and nitrogen. Therefore, it can be expected that during a thermochemical treatment, e.g. plasma nitriding, such materials will develop a large thick- ness of nitriding layer. Ferkel et al. [6] reported that sever deformation of $\mathrm{X} 5 \mathrm{CrNi} 1810$ steel $\mathrm{rf}$ nitrided at $350^{\circ} \mathrm{C}$ can enhance the nitrogen diffusion. This enhancement may be attributed to an increased grain boundary area and dislocation density. In the present investigation, an attempt has been made to evaluate the effect of kind rolling prior to rf plasma nitriding mainly on the properties of $\mathrm{Fe}_{93} \mathrm{Ni}_{4} \mathrm{Ti}_{3}$ samples. After rf plasma nitriding, the surface microhardness, nitrogen diffusion layer thickness, surface morphology and formed phases have been analyzed using a Vickers microhardness tester, optical microscopy $(\mathrm{OM})$ and $\mathrm{x}$-ray diffraction (XRD).

\section{Experimental Procedure}

The material studied was $\mathrm{Fe}_{93} \mathrm{Ni}_{4} \mathrm{Ti}_{3}$ iron-based alloy. Cupon-shaped specimens $1 \mathrm{~cm} \times 2 \mathrm{~cm}$ in diameter and 2 $\mathrm{mm}$ thick. The cupons were prepared by arc-melting pure metals with nominal purities of 99.99 wt.\% in an induction furnace under an argon atmosphere $(99.9999 \%$ purity). The produced castings were heated at $900^{\circ} \mathrm{C}$ for two hours. The heated specimens were hot rolled with about $10 \%$ reduction each time at $800^{\circ} \mathrm{C}$ up to $2 \mathrm{~mm}$ thickness. After the initial hot rolling, these specimens 
were divided into to two groups. One was rolled at room temperature (cold rolled) and the other was rolled at $900^{\circ} \mathrm{C}$ (hot rolled). Nitriding treatment of specimens was carried out using a radio frequency (rf) inductively coupled glow discharge, with a continuous mode of operation at $13.56 \mathrm{MHz}$. The nitriding system consists of a quartz reactor tube with $500 \mathrm{~mm}$ in length and $41.5 \mathrm{~mm}$ in diameter evacuated by a two-stage rotary pump to a base pressure of $10^{-2}$ mbarr. Iron-based alloy samples were supported on copper sample holder fitted which were equipped with water cooling pipes. Nitrogen $\left(\mathrm{N}_{2}\right)$ was introduced to establish a gas pressure of 8-8.4 $\times 10^{-2}$ mbar, measured with a pirani gauge. The distance between the sample holder surface and the rf coil was 2.9 $\mathrm{cm}$ and the water cooling rate for samples was 1500 $\mathrm{cm}^{3} / \mathrm{min}$. The discharge is generated by an induction copper coil energized by rf power generator (type HFS 2.5 KW, $13.65 \mathrm{MHz}$ ) via a tunable matching network. The surface morphologies and cross-sectional micrographs were examined using an optical microscope. The phase compositions of the surface region of the nitrided layer were studied by X-ray diffraction (XRD) using $\mathrm{CuK} \alpha$ radiation in the $\theta-2 \theta$ gemoetry. The microhard- ness was measured by using a Wetzlar microhardness tester with the load of $0.98 \mathrm{~N}(100 \mathrm{~g})$.

\section{Results and Discussion}

\subsection{Cross-Section Analysis by Optical Microscope}

An optical micrograph (OM) cross-section study was employed to determine the thickness of the nitrided cross-section layer (compound layer) of cold and hot (at $900^{\circ} \mathrm{C}$ ) rolled $\mathrm{Fe}_{93} \mathrm{Ni}_{4} \mathrm{Ti}_{3}$ samples. The typical cross section views of nitrided samples treated for 10 minutes using different input plasma power levels of 300, 350, $400,425,450,475,500,525$ and $550 \mathrm{~W}$ are shown in Figure 1 (for cold) and in Figure 2 (for hot at $900^{\circ} \mathrm{C}$ ) rolled treatments, respectively. From Figures 1(a) and (b) and 2(a) and (b), it can be seen that in both types of rolling, the two samples which were nitrided at 300 and 350 $\mathrm{W}$ do not contain any observed compound layer. This behavior can be attributed to low plasma processing power (from $300 \mathrm{~W}$ to $350 \mathrm{~W}$ ) where the mobility of ni-

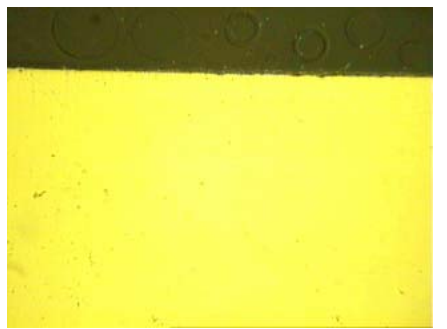

(a)

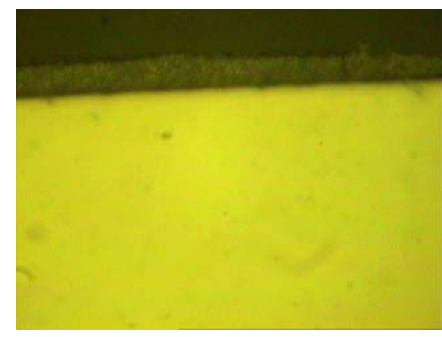

(d)

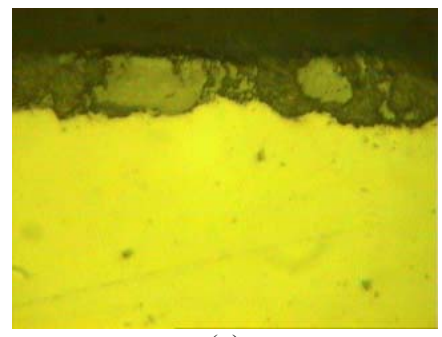

(g)

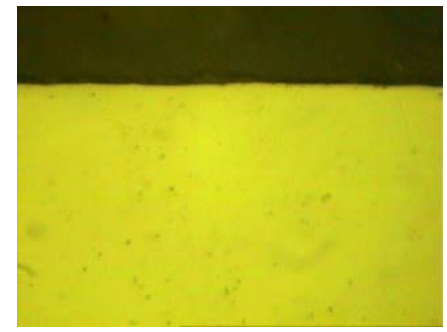

(b)

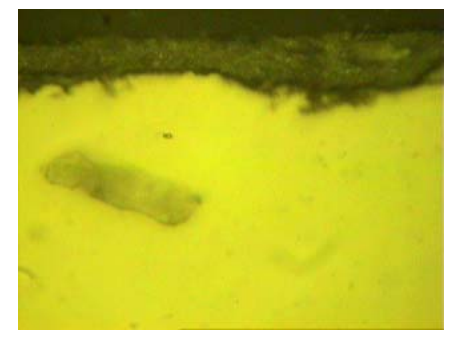

(e)

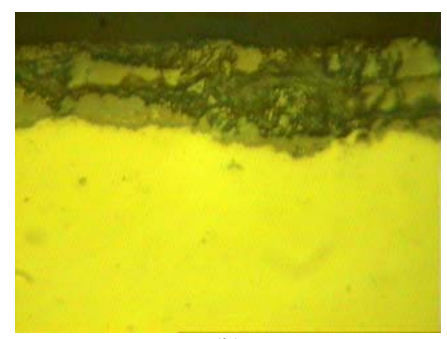

(h)

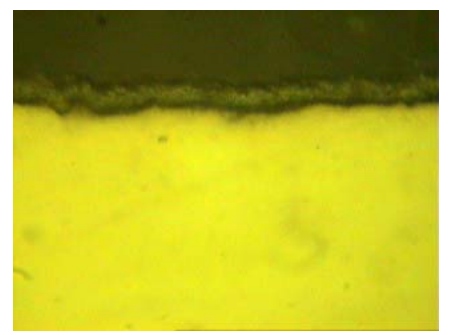

(c)

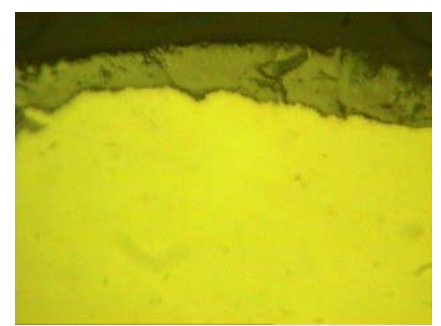

(f)

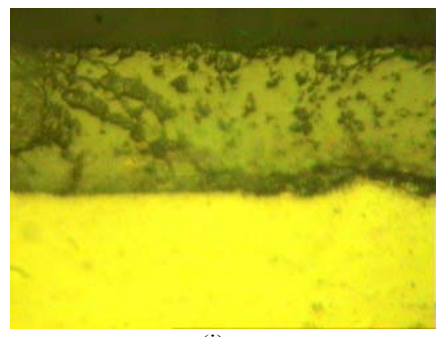

(i)

$53 \mu \mathrm{m}$

Figure 1. Optical micrographs of compound layer thickness of cold rolled samples $\mathrm{Fe}_{93} \mathrm{Ni}_{4} \mathrm{Ti}_{3}$ treated at various plasma processing power input: (a) $300 \mathrm{~W}$; (b) $350 \mathrm{~W}$; (c) $400 \mathrm{~W}$; (d) $425 \mathrm{~W}$; (e) $450 \mathrm{~W}$; (f) $475 \mathrm{~W}$; (g) $500 \mathrm{~W}$; (h) $525 \mathrm{~W}$; (i) $550 \mathrm{~W}$. 


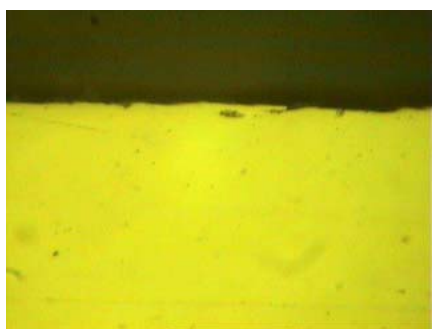

(a)

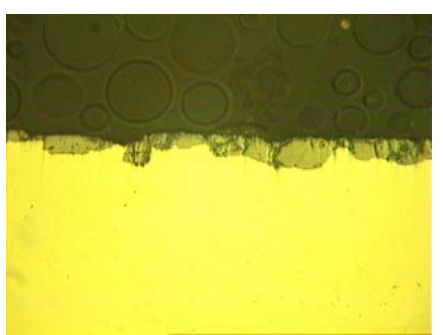

(d)

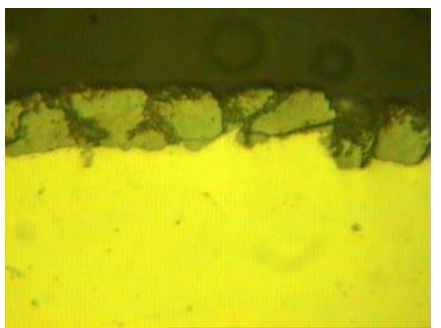

(g)

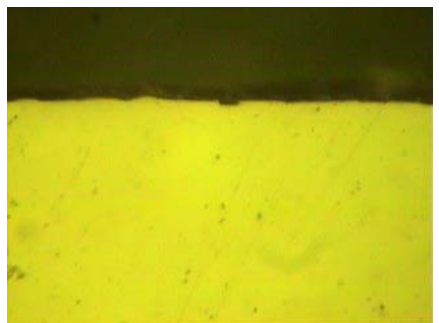

(b)

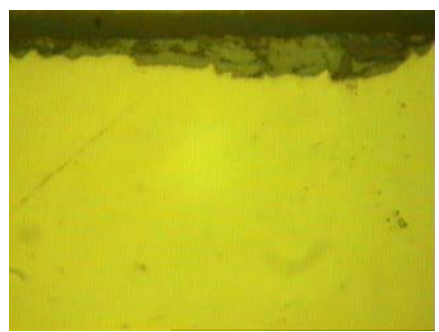

(e)

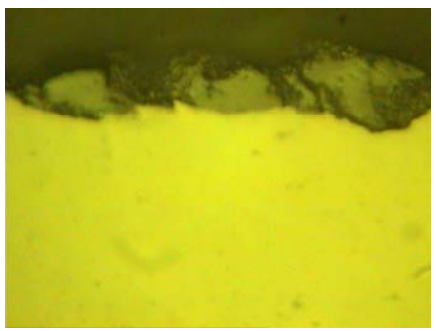

(h)

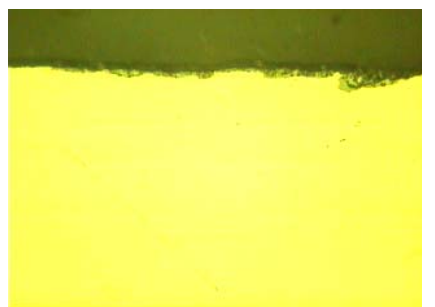

(c)

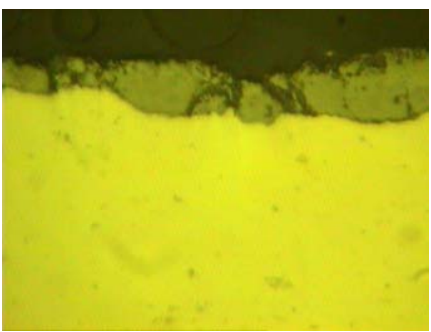

(f)

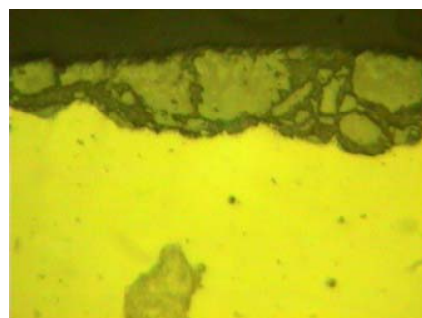

(i)

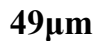

Figure 2. Optical micrographs of compound layer thickness of hot rolled samples $\mathrm{Fe}_{93} \mathrm{Ni}_{4} \mathrm{Ti}_{3}$ at $900^{\circ} \mathrm{C}$ treated at various plasma processing power input. (a) $300 \mathrm{~W}$; (b) $350 \mathrm{~W}$; (c) $400 \mathrm{~W}$; (d) $425 \mathrm{~W}$; (e) $450 \mathrm{~W}$; (f) $475 \mathrm{~W}$; (g) $500 \mathrm{~W}$; (h) $525 \mathrm{~W}$ and (i) $550 \mathrm{~W}$.

trogen atoms is low and penetration is done more easilythrough grain boundaries [7]. When the plasma power input is increases with increasing the input plasma power from $400 \mathrm{~W}$ to $550 \mathrm{~W}$ for cold and hot rolled samples, respectively. The variation range of the layer thickness is $15 \mu \mathrm{m}$ to $79 \mu \mathrm{m}$ for cold rolled while from $11 \mu \mathrm{m}$ to 56 $\mu \mathrm{m}$ for hot rolled at $900^{\circ} \mathrm{C}$. This enhancement of thickness for the cold rolled samples is probably due to the promotion of nitrogen ionization, leading to high concentrations of high-energy ions supplied onto the specimen. However, this result agrees with Mahboubi et al. [7]. Also, Ferkel et al. [8] reported that, the cold high pressure torsion (HPT) processed material shows a thicker and more homogeneous compound layer than the material not subjected to HPT; the nitrogen uptake is largest in the HPT-processed material.

\subsection{Compound Layer Thickness}

The variation of the compound layer thickness of cold rolled $\mathrm{Fe}_{93} \mathrm{Ni}_{4} \mathrm{Ti}_{3}$ and hot rolled $\mathrm{Fe}_{93} \mathrm{Ni}_{4} \mathrm{Ti}_{3}$ at $900^{\circ} \mathrm{C}$ ni- trided samples for different input plasma power are shown in the Figures $\mathbf{3}$ and $\mathbf{4}$ respectively. However, these values of thickness are measured from the cross section morphology. From these figures, for both the kinds of rolling, one can see that the thickness increases continuously as the plasma power increases. The enhancement of thickness is probably due to the domination of lattice and the penetration of nitrogen atoms through the grains, which all enhance the formation of a more uniform compound layer [8].

\subsection{Surface Morphology}

Figure 5 shows typical OM micrograph of the surface features of untreated and treated cold rolled $\mathrm{Fe}_{93} \mathrm{Ni}_{4} \mathrm{Ti}_{3}$ samples for different plasma processing power. The micrograph of the untreated sample is shown in Figure 5(a). This figure appears to be a relatively coarse-grained structure composed of iron $\alpha$-phase. The micrographs of treated samples at $300 \mathrm{~W}$ and $350 \mathrm{~W}$ are shown in Figures 5(b) and (c), which reveal no observed change in 


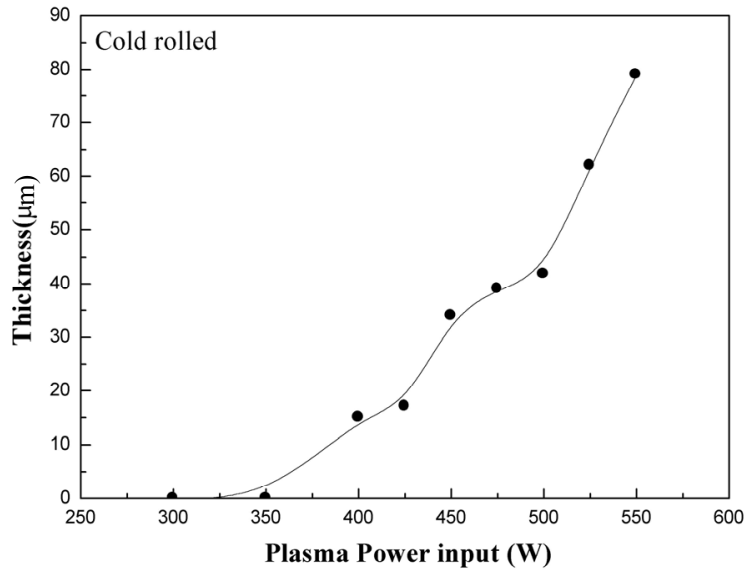

Figure 3. Thickness of compound layer as a function of plasma power for cold rolled samples of $\mathrm{Fe}_{93} \mathrm{Ni}_{4} \mathrm{Ti}_{3}$.

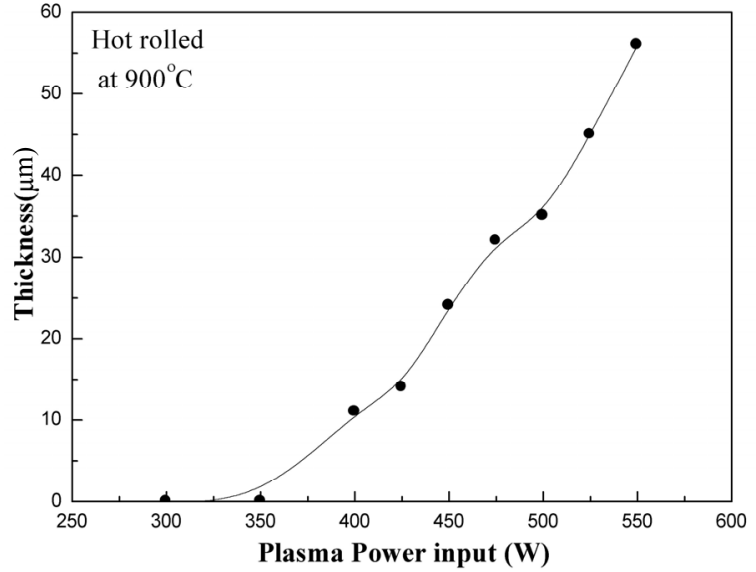

Figure 4. Thickness of compound layer as a function of plasma power for hot rolled samples of $\mathrm{Fe}_{93} \mathrm{Ni}_{4} \mathrm{Ti}_{3}$ at $900^{\circ} \mathrm{C}$.

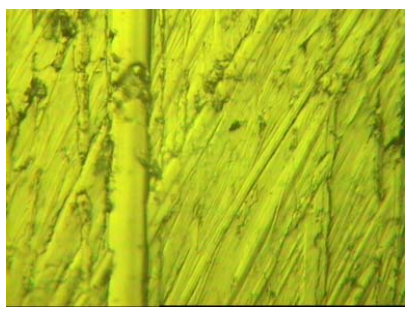

(a)

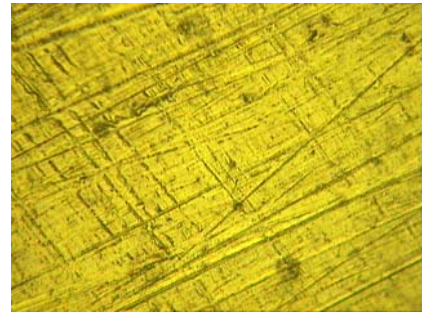

(d)

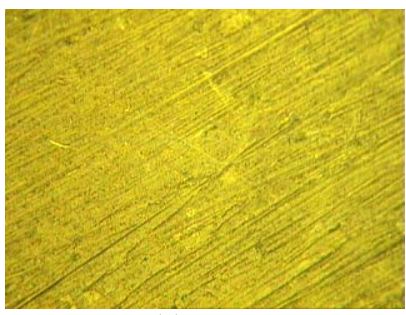

(g)

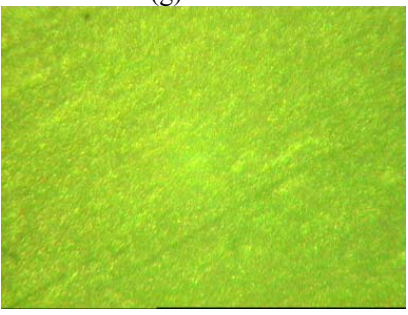

(j)

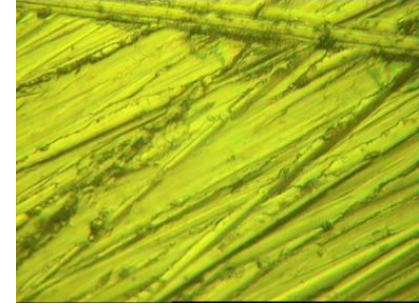

(b)

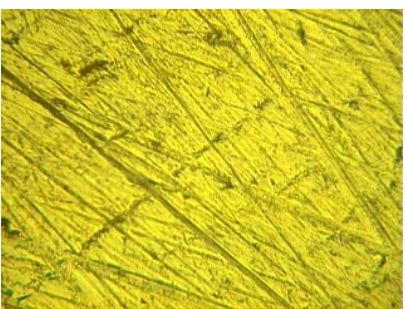

(e)

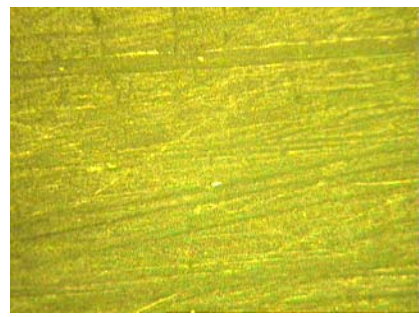

(h)

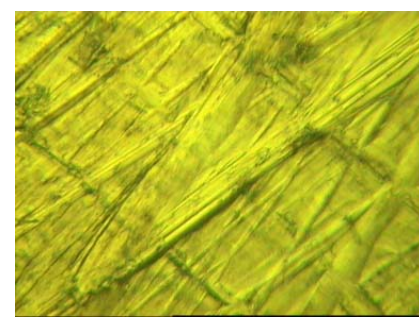

(c)

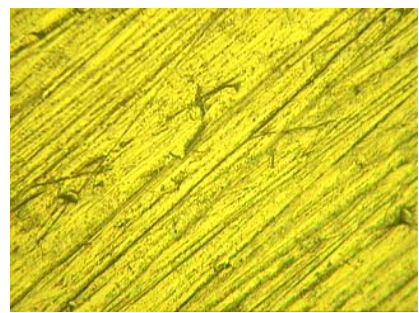

(f)

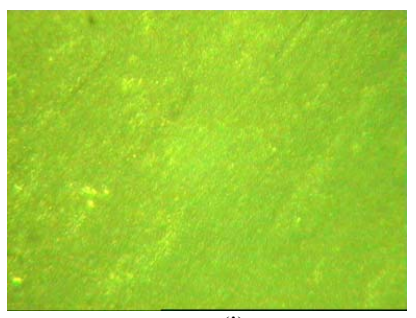

(i)

$53 \mu \mathrm{m}$

Figure 5. Optical micrographs of the surface morphology of cold rolled samples $\mathrm{Fe}_{93} \mathrm{Ni}_{4} \mathrm{Ti}_{3}$ for plasma processing power input (a) $0.0 \mathrm{~W}$; (b) $300 \mathrm{~W}$; (c) $350 \mathrm{~W}$; (d) $400 \mathrm{~W}$; (e) $425 \mathrm{~W}$; (f) $450 \mathrm{~W}$; (g) $475 \mathrm{~W}$; (h) $500 \mathrm{~W}$; (i) $525 \mathrm{~W}$; (j) $550 \mathrm{~W}$. 
the microstructure with respect to the native sample. It means that, this range of plasma processing power is not adequate to form a clear compound layer. Figures 5(d-j) shows a different microstructure with respect to the above samples as plasma power increases from $400 \mathrm{~W}$ to 550 $\mathrm{W}$. This microstructure is finer and finer in scale, as a result of the increased nitrogen solubility and diffusivity produced by the rf plasma process. This observation agrees with Pantazopoulos et al. [9], in which they reported that the liquid nitrocarburised of cold work steel exhibits a very different microstructure with respect to native sample.

\subsection{Phase Analysis by XRD Diffraction}

The X-ray diffraction patterns with $\mathrm{CuK} \alpha$ radiation was used to clarify the effect of kind rolling on the formed phases in the original and nitrided samples at different input plasma processing powers. Figures 6(a) and 7(a) show the diffraction patterns of the original samples of cold and hot (at $900^{\circ} \mathrm{C}$ ) rolled $\mathrm{Fe}_{93} \mathrm{Ni}_{4} \mathrm{Ti}_{3}$, respectively. These figures reveal that all intense peaks are assigned to $\alpha$-Fe-phase. The same diffractgrams can be seen in Figures 6(b) and 7(b) for the nitrided samples of cold and hot rolled $\mathrm{Fe}_{93} \mathrm{Ni}_{4} \mathrm{Ti}_{3}$ respectively, when the plasma power input is increased to $350 \mathrm{~W}$. When plasma power input was increased to $450 \mathrm{~W}$ and $550 \mathrm{~W}$ for cold nitrided samples, the most intense peaks are assigned to $\varepsilon$ $\mathrm{Fe}_{2-3} \mathrm{~N}$ and $\gamma^{\prime}-\mathrm{Fe}_{4} \mathrm{~N}$ phases while the peaks of $\alpha$-phase are disappeared as shown in Figures 6(c-d). It is worth mentioning that hcp $\varepsilon$-nitride exhibits a higher hardness than fcc- $\gamma$-nitride [10]. Figure 7(c) shows the diffraction peaks of the hot nitrided sample when plasma power input was adjusted to $450 \mathrm{~W}$. From this figure, only $\varepsilon$-phase can be detected while the peaks of $\alpha$ and $\gamma^{\prime}$ phases have disappeared. When plasma power input reached

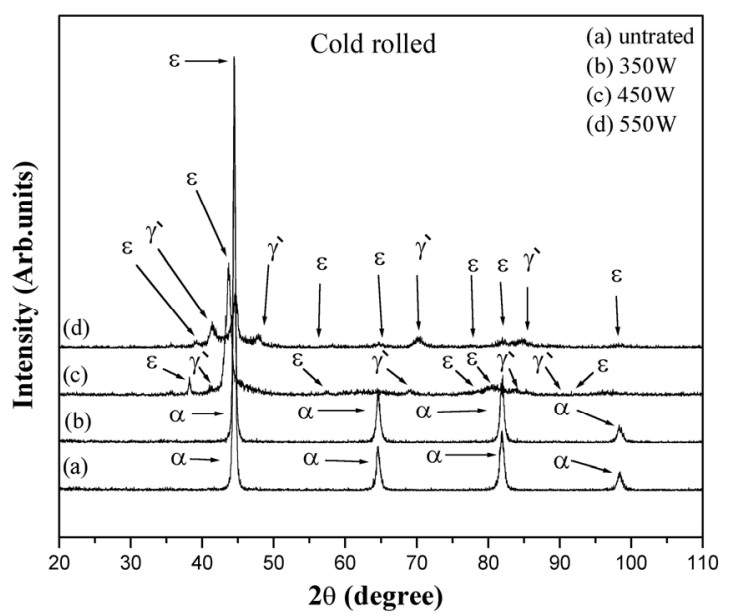

Figure 6. X-ray diffraction patterns for $\mathrm{Fe}_{93} \mathrm{Ni}_{4} \mathrm{Ti}_{3}$ samples (a) untreated cold rolled and treated for plasma processing powers; (b) $350 \mathrm{~W}$; (c) $450 \mathrm{~W}$; (d) $550 \mathrm{~W}$.

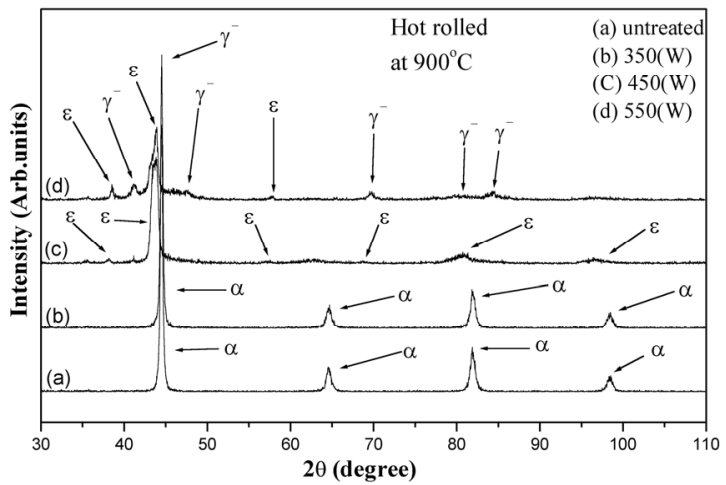

Figure 7. X-ray diffraction patterns for $\mathrm{Fe}_{93} \mathrm{Ni}_{4} \mathrm{Ti}_{3}$ samples (a) untreated hot rolled at $900^{\circ} \mathrm{C}$ and treated for plasma processing powers; (b) $350 \mathrm{~W}$; (c) $450 \mathrm{~W}$; (d) $550 \mathrm{~W}$.

550W for the same sample in Figure 7(d), the intense peaks of $\gamma^{\prime}$-phases emerge, while the peaks of $\varepsilon$-phase decrease significantly. From the above results, the following observations are made: 1) In both the types of rolled samples, the peaks of NiN and TiN cannot be detected. 2) The peak ratio of $\varepsilon$-phase to $\gamma^{\prime}$-phase increases by increasing plasma power input from $450 \mathrm{~W}$ to $550 \mathrm{~W}$ for cold rolled samples, while it decreases at the same condition for hot rolled samples. It can be concluded that this is the reason for continuous increase in the microhardness for the cold rolled treated samples after nitrided for $450 \mathrm{~W}$, while the microhardness abruptly decreases for the hot rolled treated samples after nitrided for the same power (see the next paragraph). 3) The influence of the Ni present in the samples has not been considered, because the interaction of $\mathrm{Ni}$ with $\mathrm{N}$ that is even weaker than the interaction between $\mathrm{N}$ and Fe. However, these observations agree well with Chezan et al. [11], in which they reported that the severe deformation caused by cold rolling for $\mathrm{Fe}-\mathrm{Ni}-\mathrm{Ti}$ and $\mathrm{Fe}-\mathrm{Ni}-\mathrm{Cr}$ leads to formation of large density nucleation sites for new phases, i.e. $\gamma^{\prime}$ and $\varepsilon$.

\subsection{Microhardness Measurements}

In order to clarify the influence of kind rolling on the mechanical properties of nitrided samples, microhardness measurements of nitrided cold rolled and hot rolled (at $900^{\circ} \mathrm{C}$ ) $\mathrm{Fe}_{93} \mathrm{Ni}_{4} \mathrm{Ti}_{3}$ samples were performed at a load of $\mathrm{P}=100 \mathrm{~g}(0.89 \mathrm{~N})$.

Figure 8 displays the variation of microhardness val-ues of untreated and nitrided cold rolled samples $\mathrm{Fe}_{93}$ $\mathrm{Ni}_{4}-\mathrm{Ti}_{3}$ against the input plasma power. From this figure, one can notice that the microhardness value of the nitrided samples at $300,350 \mathrm{~W}$ equals nearly the same value of untreated sample $297 \mathrm{HV}$. This trend is probably due to the fact that at $350 \mathrm{~W}$ and below, there is not enough rf power to create precipitation, which would lead to significant hard phases. This result is confirmed by XRD analysis and OM observations. When plasma power in 


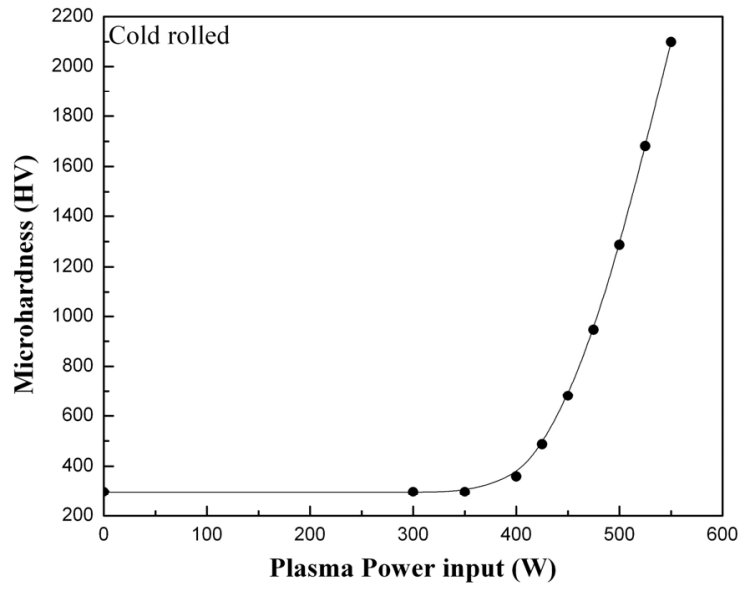

Figure 8. Microhardness values of untreated and treated cold rolled $\mathrm{Fe}_{93} \mathrm{Ni}_{4} \mathrm{Ti}_{3}$ samples for different plasma power input.

put increases from 400 to $550 \mathrm{~W}$, the microhardness value increases exponentially to reach the value of 2098 HV. This represents a 7-fold increase in the surfacehardness comparing with the untreated sample (282 HV). The anomalously high microhardness values are due to the fact that high defect density in nitrided samples offers enough nucleation sites for nitrides and enough diffusion paths for nitrogen. In this case, a dense compound layer with high hardness can easily form [6]. Also, the dramatic increase of hardness is a result of compressive stresses, which is induced in the target surface by the cold rolling and a compound layer produced on the target surface by nitriding.

Figure 9 depicts the variation of microhardness values of untreated and nitrided hot rolled (at $900^{\circ} \mathrm{C}$ ) samples $\mathrm{Fe}_{93} \mathrm{Ni}_{4} \mathrm{Ti}_{3}$ against the input plasma power. From this figure, one can notice that the microhardness values of the nitrided samples at $300 \mathrm{~W}$ and $350 \mathrm{~W}$ equal nearly the same value of untreated sample $274 \mathrm{HV}$. As plasma power input increases from $400 \mathrm{~W}$ to $450 \mathrm{~W}$, the microhardness value increases continuously to reach the value of $572 \mathrm{HV}$; this represents a 2-fold increase in the surface hardness comparing with untreated sample. This trend may be credited to the formation of a compound layer thickness of $11 \mu \mathrm{m}$ to $56 \mu \mathrm{m}$, which contains a high concentration of nitrogen [12]. Similar behavior has been observed by Devi and Mohanty [13], in which a microhardness value of $1478 \mathrm{HV}$ in hot rolled D2 steel was achieved after plasma nitriding at $510^{\circ} \mathrm{C}$ for $18 \mathrm{~h}$. With the high input plasma power of $475 \mathrm{~W}$ or more, the microhardness value decreases. This reduction can be attributed to the decrease the ratio of $\varepsilon$-phase to $\gamma^{\prime}$-phase [10]. However, this result agrees well with XRD analysis.

In light of the microhardness measurements, it can be concluded that a general hardness increase for cold rolled treated samples can be associated with enhancement of

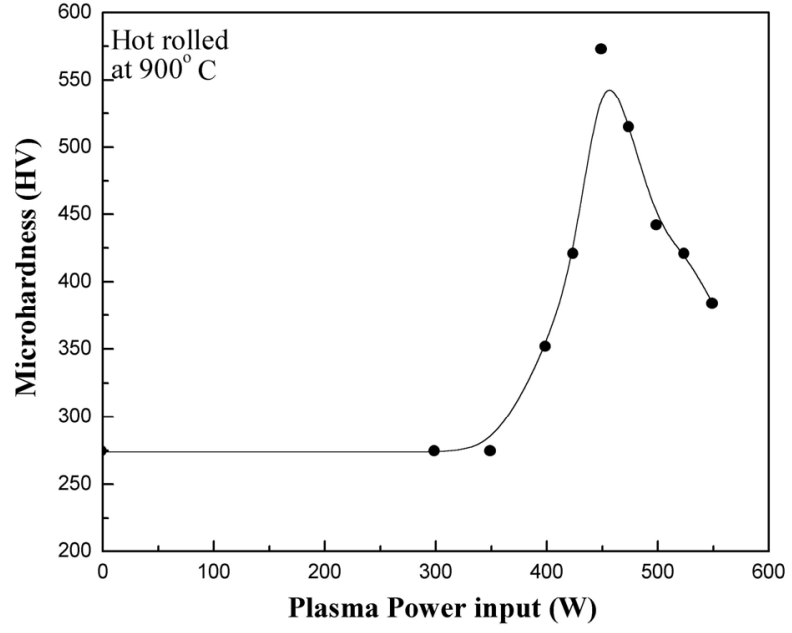

Figure 9. Microhardness values of untreated and treated hot rolled $\mathrm{Fe}_{93} \mathrm{Ni}_{4} \mathrm{Ti}_{3}$ at $900^{\circ} \mathrm{C}$ samples for different plasma power input.

defect density and/or a compressive stress. i.e., the hardness of the plasma nitrided sample shows a kind of rolling dependent behavior.

\section{Conclusions}

The thickness, hardness and phase composition of the modified layer formed on cold and hot rolled nitrided $\mathrm{Fe}_{93} \mathrm{Ni}_{4} \mathrm{Ti}_{3}$ are investigated in this work. All of the samples were hardened by forming nitrided layers. The advantage of the pre-cold rolling is that a thicker nitrided layer with higher hardness is formed. The cold rolling process is a well-known technique applied to improve the mechanical properties of steel surfaces. Through this process, a large number of grain boundaries, dislocations and positive holes form through the surface of specimens, which all enhance the nitrogen diffusion. The surface hardness of nitrided cold-rolled $\mathrm{Fe}_{93} \mathrm{Ni}_{4} \mathrm{Ti}_{3}$ samples represents a 3.7-fold increase with respect to the nitrided hot-rolled samples. This trend may be credited to the high defect density of nitrided cold rolled samples, which offers enough nucleation sites for nitrides and enough diffusion paths for nitrogen [12]. The modified surface of nitrided cold rolled samples is characterized with a finer microstructure. The phase analysis dictates that the peak ratio of $\varepsilon$ to $\gamma^{\prime}$ phase increases by increasing plasma power input from 450 to $550 \mathrm{~W}$ for nitrided cold rolled samples, while it decreases at the same conditions for nitrided hot-rolled samples. This is the reason behind the continuous increase in the microhardness for the cold rolled treated samples after application of $450 \mathrm{~W}$ plasma power, with a decrease for the hot rolled treated samples after being nitrided for the same power. The most striking results of this work are the increased thickness of the nitrided cold rolled samples. Indeed, diffusion of nitro- 
gen by the microcracks mechanism could be expected to be significantly affected by an increase in grain boundary area as a result of cold rolling. However, the experimental evidence demonstrates that the microstructure of cold rolled material does have a significant influence on nitrogen diffusion.

\section{Acknowledgments}

The authors would like to thank Prof. T. Munsat at the University of Colorado for his help in preparing this manuscript.

\section{References}

[1] F. M. El-Hossary, "The Influence of Surface Microcracks and Temperature Gradients on the Rf Plasma Nitriding Rate," Surface and Coatings Technology, Vol. 150, No. 2, 2002, pp. 277-281.

[2] F. M. EL-Hossary, N. Z. Negm, S. M. Khalil, A. M. Abd Elrahman and D. N. Mcllroy, "RF Plasma Carbonitriding of AISI Austenitic Stainless Steel," Surface and Coatings Technology, Vol. 141, No. 2-3, 2001, pp. 194-201.

[3] C. B. Craus, A. R. Chezan, N. G. Chechenin, D. O. Boerma and L. Niesen, "Soft Magnetism in Nitrided $\mathrm{Fe}_{93} \mathrm{Ni}_{4} \mathrm{Cr}_{3}$ and $\mathrm{Fe}_{94} \mathrm{Ni}_{4} \mathrm{Ti}_{2}$ Cold-Rolled Alloys," Journal of Magnetism and Magnetic Materials, Vol. 263, No. 1-2, 2003, pp. 47-56.

[4] G. Edrem and Y. Taptik, "Effect of Hot Rolling Conditions to Produce Deep Drawing Quality Steels for Continuous Annealing Process," Journal of Material Processing Technology, Vol. 170, No. 1-2, 2005, pp. 17- 23.

[5] H. Katoh, H. Takachi, N. Takahashi and M. Abe, "Cold Rolled Steel Sheets Produced by Continuous Annealing, Technology Continuously Annealed Cold-Rolled Steel," 1984, pp. 37-38.
[6] H. Ferkel, M. Glatzer, Y. Estrin and R. Z. Valiev, "RF Plasma Nitriding of Severely Deformed High Alloyed Steel," Scripta Material Science, Vol. 46, No. 9, 2002, pp. 623-628.

[7] F. Mahboubi and K. Abdolvahabi, "The Effect of Temperature on Plasma Nitriding Behavior of DIN 1.6959 Low Alloy Steel," Vacuum, Vol. 81, No. 3, 2006, pp. 239-243.

[8] H. Ferkel, M. Glatzer, Y. Estrin, R. Z. Valiev, C. Blawert and B. L. Mordike, "RF Plasma Nitriding of Severely Deformed Iron-Based Alloys," Materials Science and Engineering A, Vol. 348, No. 1-2, 2003, pp. 100-110.

[9] G. Pantazopoulos, P. Psyllaki, D. Kanakis, S. Antoniou, K. Papadimitriou and J. Sideris, "Tribological Properties of a Liquid Nitrocarburised Special Purpose Cold Work Tool Steel," Surface and Coatings Technology, Vol. 200, No. 20-21, 2006, pp. 5889-5895.

[10] H. Ferkel, Y. Estrin, C. Blawert and R. Z. Valiev, "RF Nitriding of Severely Deformed Armco Iron and St2 K50," Surface and Coatings Technology, Vol. 173-174, 2003, pp. 1164-1170.

[11] A. R. Chezan, C. B. Craus, N. G. Chechenin, T. Vystavel, L. Niesen, J. T. M. De Hosson and D. O. Boerma, "On the Formation of Ultra-Fine Grained Fe-Base Alloys Via Phase Transformations," Materials Science and Engineering A, Vol. 367, No. 1-2, 2004, pp. 176-184.

[12] F. M. El-Hossary, S. M. Khalil, K. Lotfy and M. A. Kassem, "The Influence of Hot-Rolled Temperature on Plasma Nitriding Behavior of Iron-Based Alloys," Journal of Low Temperature Physics, Vol. 156, No. 1-2, 2009, pp. 38-47.

[13] M. U. Devi and O. N. Mohanty, "Plasma-Nitriding of Tool Steels for Combined Percussive Impact and Rolling Fatigue Wear Applications," Surface and Coatings Technology, Vol. 107, No. 1, 1998, pp. 55-64. 